Departamento de Higiene e Polícia Sanitária Animal Diretor: Prof. Dr. Theodoro Lion de Araujo

Departamento de Química Orgânica e Biológica Diretor: Prof. Dr. Fonseca Ribeiro

\title{
SEMI-MICRO MÉTODO FOTOMÉTRICO DE DOSAGEM DO FERRO, PELO ÁCIDO PROTOCATECÚICO, NA TERRA
}

\section{Arnaldo Costa e Virgilio Bonoldi \\ Assistentes}

E' corrente nas análises de terra a determinação do ferro, sem que ela tenha, é verdade, a mesma importância que a do fósforo, alcalinos e alcalinos-terrosos. Ao lado da sílica, silicatos a mesma é feita com o objéto de fornecer dados que possibilitem estabelecer, por um lado, qual a cultura adequada para o terreno em apreço, por outro, decidir da adição do adubo com que satisfazer as exigências desta ou daquela cultura.

Na prática corrente a determinação do ferro é feita por métodos que conduzem à dosagem, por permanganatometría ou por precipitação (1). Ambos exigem, entretanto, uma série de operações que tornam trabalhosa a determinação. Sugeriu-nos isto, diante da simplicidade do método fotométrico para a determinação do ferro, proposto por R. S. PEREIRA (2), verificar da sua aplicabilidade na determinação do citado elemento na terra.

\section{PARTE EXPERIMENTAL}

A terra fina, depois de cuidadosamente sêca, foi submetida a digestão nítrica pelo espaço de cinco horas, findas as quais diluiu-se a volume conhecido, diluição esta condicionada a presumivel maior ou menor riqueza de ferro na amostra. Numa aliquota, depois de eliminado o ácido nítrico com o auxílio do ácido sulfúrico sem o que não obtivemos resultados satisfatórios, procedeu-se a determinação do ferro de acôrdo com o referido método do ácido protocatecúico. (2).

MÉ T O D O

SEMI-MICRO MÉTODO FOTOMÉTRICO DE DOSAGEM DO FERRO, PELO ÁCIDO PROTOCATECÚCOCO, NA TERRA

De 50 a $100 \mathrm{mg}$ de terra fina, cuidadosamente sêca, são submetidos a digestão nítrica, pelo espaço de cinco horas, em banho maria em Erlenmeyer de $50 \mathrm{~cm}^{3}$ de capacidade, usando-se para cada amostra $3 \mathrm{~cm}^{3}$ de ácido nitrico $\mathrm{D} .=1,4$, isento de ferro. $\mathrm{O}$ resultado da diges- 
Quadro I

DETERMINAÇÃo DO FERRO NA TERRA PELO MÉTODO ÁCIDO PROTOCATECÚICO NA MESMA AMOSTRA DE TERRA FINA

\begin{tabular}{|c|c|c|c|c|c|c|}
\hline $\begin{array}{l}\text { Substância } \\
\text { sêca } \\
\text { terra fina } \\
\text { mg }\end{array}$ & $\begin{array}{l}\text { Volume } \\
\text { de diluięão } \\
\text { após a } \\
\text { digestăo } \\
\text { nítrica }\end{array}$ & $\begin{array}{l}\text { Aliquota } \\
\text { tomada }\end{array}$ & $\begin{array}{c}\text { Volume } \\
\text { em que foi } \\
\text { a côr } \\
\text { desenvolvida }\end{array}$ & $\begin{array}{l}\text { D } \\
\text { Por cento } \\
\text { de trans- } \\
\text { parência }\end{array}$ & $\begin{array}{c}\text { K } \\
\text { Coeficiente } \\
\text { de } \\
\text { extinçäo }\end{array}$ & $\begin{array}{l}\text { Por cento em } \\
\text { mg de Fe na } \\
\text { amostra }\end{array}$ \\
\hline 50,3 & 50 & 0,5 & 10 & 73,5 & 0,134 & 0,2477 \\
\hline 32,4 & 10 & 0,1 & 10 & 81,8 & 0,088 & 0,2525 \\
\hline 51,3 & 50 & 0,5 & 10 & 74,5 & 0,128 & 0,2320 \\
\hline 59,1 & 50 & 0,5 & 10 & 69,8 & 0,156 & 0,2454 \\
\hline 44,8 & 50 & 0,5 & 10 & 77,5 & 0,111 & 0,2304 \\
\hline 36,7 & 10 & 0,1 & 10 & 79,5 & 0,099 & 0,2508 \\
\hline 56,3 & 50 & 0,5 & 10 & 71,5 & 0,146 & 0,2411 \\
\hline 54,7 & 50 & 0,5 & 10 & 72,5 & 0,140 & 0,2380 \\
\hline 55,7 & 50 & 0,5 & 10 & 73,5 & 0,134 & 0,2237 \\
\hline
\end{tabular}

Todas as leituras foram feitas no fotômetro do Pulfrich com cuba de $1 \mathrm{~cm}$.
Média $=0,24017$
D. P. $=\sigma=0,0099$
C. V. $=\sigma_{\mathrm{v}}=4,1$

Quadro II

EXPERIÊNCIA DE RECUPERAÇÃO

\begin{tabular}{c|c|c|c|c|c|c}
\hline Amostra & $\begin{array}{c}\text { Terra fina } \\
\text { sêca } \\
\mathrm{mg}\end{array}$ & $\begin{array}{c}\text { Ferro } \\
\text { fnicial } \\
\text { pretente } \\
\mathrm{mg}\end{array}$ & $\begin{array}{c}\text { Ferro } \\
\text { adieionado } \\
\mathrm{mg}\end{array}$ & $\begin{array}{c}\text { Ferro total } \\
\text { encontrado } \\
\text { mg }\end{array}$ & $\begin{array}{c}\text { Ferro } \\
\text { recuperado } \\
\text { mg }\end{array}$ & $\begin{array}{c}\text { Ferro } \\
\text { recupersdo } \\
\text { por cento }\end{array}$ \\
\hline \hline & & 0,1242 & 0,0521 & 0,1763 & 0,0506 & 97 \\
2 & 53,1 & 0,1022 & 0,0433 & 0,1455 & 0,0416 & 96 \\
3 & 69,1 & 0,1331 & 0,0505 & 0,1836 & 0,0541 & 107 \\
4 & 75,4 & 0,1452 & 00632 & 0,2084 & 0,0591 & 93,5 \\
5 & 60,2 & 0,1159 & 0,0457 & 0,1616 & 0,0471 & 103 \\
6 & 68,7 & 0,1423 & 0,0527 & 0,1950 & 0,0538 & 102 \\
7 & 56,8 & 0,1094 & 0,0444 & 0,1538 & 0,0445 & 100 \\
8 & 72,9 & 0,1404 & 0,0537 & 0,1941 & 0,0571 & 106 \\
9 & 63,7 & 0,1227 & 0,0526 & 0,1753 & 0,0500 & 95 \\
& & & & & Média $=99,95$ \\
\hline
\end{tabular}

Os resultados acima evidenciam a aplicabilidade do método fotométrico do ácido protocatecúico, à determinação do ferro na terra. 
tão é diluido com água distilada e transportado para um frasco aferido, de 50 ou $100 \mathrm{~cm}^{3}$. Filtra-se ou deixa-se repousar. Transfere-se para tubo de ensaio Pyrex possuindo graduação de $10 \mathrm{~cm}^{3}$, um volume de $0,5 \mathrm{~cm}^{3}$ ou $1 \mathrm{~cm}^{3}$ dessa diluição. Junta-se à aliquota transferida ao tubo Pyrex, 3-4 gôtas de ácido sulfúrico $10 \mathrm{~N}$ cerca, e, à chama de bico de Bunsen, elimina-se o ácido nítrico. Essa eliminação reconhece-se pela formação de vapores densos de anidrido sulfúrico. Uma vez o tubo frio, lavam-se as paredes do mesmo com $3-4 \mathrm{~cm}^{3}$ de água distilada e procede-se ao desenvolvimento de côr de acôrdo com o método do ácido protocatecúico de R. S. PEREIRA (2). Da publicação dêste autor juntamente com A. Costa (3), retiramos o seguinte, referente aos reativos e a maneira de operar.

\section{REATIVOS NECESSÁRIOS}

a) Citrato de amônio a $20 \%$.

b) Ácido protocatecúico. Solução a $1 \% \mathrm{em}$ alcool etílico a $50 \%$.

c) Hidróxido de amônio $2 \mathrm{~N}$.

d) Solução $\mathrm{N}$ de sulfato de amônio - solução $\mathrm{N}$ de amoníaco (4:1).

Quer se tome a totalidade da solução para a dosagem do ferro, quer se usem aliquotas da mesma, esta, posta em tubo de experiência graduado à altura de 5-7, 5 e $10 \mathrm{~cm}^{3}$, trata-se por $1 \mathrm{~cm}^{3}$ do reativo (a), e em seguida adicionam-se $0,2 \mathrm{~cm}^{3} \mathrm{de}$ (b) para cada $5 \mathrm{~cm}^{3}$ de volume total, e, agitando-se o tubo após cada gôta ajuntada, o reagente (c), cuidadosamente, até que se desenvolva côr vermelha, o que indica haver-se alcalinizado o meio.

Por meio do $\mathrm{SO}_{4} \mathrm{H} 2 \mathrm{~N}$, posto cautelosamente às gotas, em quantidade exatamente necessária para atingir o fim em vista, que é acidificar-se levemente o soluto, o que se reconhece pelo desaparecimento da côr vermelha, ou pela transformação desta em violeta, ou em verde azulada, passa-se para meio ácido a solução das cinzas.

Restabelece-se a côr vermelha primitiva por meio do reagente (d) e com êste perfaz-se volume convenientemente marcado na parede do tubo.

Ao mesmo tempo, e exatamente sob as mesmas condições, prepara-se um branco, que servirá de líquido de compensação. Ao cabo de 10-40 minutos determina-se a extinção dada pelo fotômetro de Pulfrich, usando o filtro S-50 e cuba de espessura conveniente".

\section{RESUMO}

Os autores aplicaram o método do ácido protocatecúico para a valoração do ferro, à determinação dêsse elemento na terra, tendo obtido, para a mesma amostra, 9 dosagens, D.P. $=\sigma=0,0099 \mathrm{e}$ C.V. $=\sigma_{\mathrm{v}}=4,1$. Trabalhando com 9 amostras de terra, na prova de recuperação, a porcentagem desta foi de $99,95 \%$. 


\section{SUMMARY}

The authors applied the method of protocatechuic acid in the determination of iron, for the analysis of this element in the earth, having obtained, in the same sample of earth, in 9 determinations, S.D. $=\sigma=0,0099$ and C.V. $=\sigma_{\mathrm{v}}=4,1$.

Working with nine samples, in the test of recuperation, the percentage in this was $99,95 \%$.

\section{BIBLIOGRAFIA}

1 - Association of Official Agricultural Chemist - 1940 - Official and Tentative Methods, 5. 5th. ed., Washington.

2 - Pereira, R. S. - 1941 - A new photometric method for the determination of iron. Journ. Biol. Chem., 137: 417, 28.

3 - Pereira, R. S. e A. Costa - 1942 - Determinação fotométrica do ferro nas fezes por meio do método do ácido protocatéquico. Rev. Fac. Med. Vet. de São Paulo, 2: 67-70. 